\title{
A Scoring Instrument to Predict the Survival Prognoses of Patients with Metastatic Epidural Spinal Cord Compression from Gynecological Malignancies
}

\author{
STEFAN JANSSEN ${ }^{1,2}$, AMIRA BAJROVIC ${ }^{3}$, STEVEN E. SCHILD ${ }^{4}$ and DIRK RADES ${ }^{1}$ \\ ${ }^{1}$ Department of Radiation Oncology, University of Lübeck, Lübeck, Germany; \\ ${ }^{2}$ Medical Practice of Radiotherapy and Radiation Oncology, Hannover, Germany; \\ ${ }^{3}$ Department of Radiation Oncology, University Medical Center Eppendorf, Hamburg, Germany; \\ ${ }^{4}$ Department of Radiation Oncology, Mayo Clinic, Scottsdale, AZ, U.S.A.
}

\begin{abstract}
Aim: To design a scoring instrument for rating overall survival (OS) of patients with metastatic epidural sinal cord compression (MESCC) from gynecological malignancies. Patients and Methods: In 22 patients treated with radiotherapy alone for MESCC from gynecological malignancies, ten factors were analyzed for effects on OS. Factors significantly associated with OS on multivariate analysis were included in a scoring instrument. Results: On multivariate analyses, no visceral metastases $(p=0.004)$ and affection of $1-2$ vertebrae $(p=0.012)$ were significant. Scoring points for each factor were 0 or 1, depending on OS rates. After summing, scores of $0(n=6), 1(n=9)$ or 2 points $(n=9)$ were obtained. OS rates were $0 \%, 78 \%$ and $100 \%$, respectively, at 3 months and $0 \%, 33 \%$ and $86 \%$, respectively, at 6 months $(p<0.001)$. Conclusion: An instrument was developed for estimating the lifespan of patients with MESCC from gynecological malignancies. This instrument can support physicians when picking an individual treatment.
\end{abstract}

Metastatic epidural spinal cord compression (MESCC) is an oncologic emergency that occurs in up to $10 \%$ of adult cancer patients $(1,2)$. Since patients with gynecological malignancies account for less than $1 \%$ of patients with MESCC, not much is known on this group. Most patients with MESCC are treated with radiotherapy alone, which was suggested to also be effective for ovarian cancer (3). Selected

Correspondence to: Professor Dirk Rades, MD, Department of Radiation Oncology, University of Lübeck, Ratzeburger Allee 160, 23538 Lübeck, Germany. Tel: +49 4515006661, Fax: +49 4515003324, e-mail: rades.dirk@gmx.net

Key Words: Gynecological cancer, MESCC, radiotherapy, overall survival, scoring instrument. patients with a good general condition and an expected lifespan of at least three months could benefit from neurosurgery prior to radiotherapy (4). Physicians should be able to rate a patient's estimated overall survival (OS) time to help them in planning treatment. Furthermore, the fractionation regimen of radiotherapy should be chosen with consideration of the patient's lifetime. It is well-agreed that patients with MESCC and a short lifespan should receive short-course radiotherapy, such as 20 Gy in 5 fractions, whereas patients with a more prolonged OS benefit from a longer-course of radiotherapy, such as $30 \mathrm{~Gy}$ in 10 fractions or $40 \mathrm{~Gy}$ in 20 fractions in terms of improved local control of MESCC and OS $(2,5,6)$. Scoring instruments identifying patient groups with different OS times enable physicians to tailor treatment to a patient's individual situation. Ideally, separate instruments would be available for each tumor entity, since prognoses and biology vary considerably between primary tumors causing MESCC. This study was conducted to create a scoring instrument specifically for MESCC from gynecological malignancies.

\section{Patients and Methods}

Twenty-two patients who were treated with radiotherapy alone for MESCC from gynecological cancer were retrospectively evaluated for OS. Four patients received shorter-course radiotherapy with $1 \times 8$ in 1 day $(n=1)$ or $5 \times 4$ Gy in 1 week $(n=3), 18$ patients longer-course radiotherapy with $10 \times 3$ Gy in 2 weeks $(n=9), 15 \times 2.5$ Gy in 3 weeks $(n=3)$ or $20 \times 2$ Gy in 4 weeks $(n=6)$. All patients had motor weakness of the legs caused by MESCC, no prior local treatment to the involved spinal parts, surgical consultation prior to radiotherapy and diagnosis of MESCC made by computed tomography or magnetic resonance imaging. Dexamethasone was given during and tapered down following radiotherapy. Radiotherapy was delivered with 6-10 MV photon beams from a modern linear accelerator and encompassed one normal vertebra above and below those involved by MESCC.

In addition to type of radiotherapy regimen, the following nine factors were analyzed: cancer site (ovarian $v s$. uterine $v s$. cervical 
$v s$. vulvar), age ( $\leq 60 v s . \geq 61$ years, median=60.5), period from diagnosis of gynecological malignancy until MESCC ( $\leq 15$ vs. $>15$ months, according to previous studies), visceral metastases (no vs. yes), other bone metastases (no vs. yes), dynamic of developing weakness of the legs prior to radiotherapy (fast: $\leq 14$ days $v s$. slow: $>14$ days, median=14.5 days), gait function prior to radiotherapy (not ambulatory $v s$. ambulatory), vertebrae affected by MESCC (1$2 v s . \geq 3$, median=2) and Eastern Cooperative Oncology Group (ECOG) performance score (1-2 vs. 3-4). Univariate analyses were performed with the Kaplan-Meier method and the log-rank test. Factors found significant $(p<0.05)$ were additionally analyzed for independence with the Cox proportional hazards model. Factors proved to be independent predictors of OS were included in the scoring instrument.

\section{Results}

On univariate analysis, no visceral metastases $(p<0.001)$, slower ( $>14$ days) development of weakness of the legs $(p=0.008)$, ambulatory status $(p=0.005)$, affection of only 1 2 vertebrae by MESCC $(p=0.020)$ and ECOG performance score of $0-1(p=0.012)$ had a significant impact on OS (Table I). Because ECOG performance score and ambulatory status were confounding variables (non-ambulatory patients had an ECOG performance score of 3-4), two multivariate analyses were performed, one including ECOG performance score and another one including ambulatory status.

On multivariate analyses, visceral metastases $(p=0.004)$ and number of vertebrae affected by MESCC $(p=0.012)$ were significant and included in the scoring instruments (Table II). The scoring points for each factor were 0 or 1 (Table III), depending on OS rates at 3 and 6 months (Table I). After summing the scoring points of both factors, prognostic scores of 0 points $(n=6), 1$ point $(n=9)$ or 2 points $(\mathrm{n}=9)$ were obtained. OS rates of these groups were $0 \%, 78 \%$ and $100 \%$, respectively, at 3 months and $0 \%, 33 \%$ and $86 \%$, respectively, at 6 months $(p<0.001$, Figure 1$)$.

\section{Discussion}

Personalized treatment approaches are increasingly popular for cancer patients with metastatic disease. The remaining lifespan of these palliative patients should be taken into consideration when evaluating the best available individual treatment. Therefore, several prognostic factors were identified and survival scores were developed for patients with metastatic cancer, including those with MESCC (7-10). The initial survival scores have been developed from patient cohorts with metastases from many different primary tumor types. Subsequently, the opinion has prevailed that separate scoring instruments for single tumor entities would be more appropriate to allow greater personalization of the treatment for patients with metastatic disease (2). No scoring instrument has been developed so far for patients with metastases from gynecological malignancies.
Table I. Overall survival rates at 3 and 6 months (univariate analyses).

\begin{tabular}{|c|c|c|c|}
\hline & $\begin{array}{l}\text { At } 3 \text { months } \\
(\%)\end{array}$ & $\begin{array}{c}\text { At } 6 \text { months } \\
(\%)\end{array}$ & $p$-Value \\
\hline \multicolumn{4}{|l|}{ Cancer type } \\
\hline Ovarian cancer $(\mathrm{n}=8)$ & 50 & 25 & \\
\hline Uterine cancer $(n=2)$ & 50 & 50 & \\
\hline Cervical cancer $(n=11)$ & 73 & 55 & \\
\hline Vulvar cancer $(\mathrm{n}=1)$ & 100 & 0 & 0.26 \\
\hline \multicolumn{4}{|l|}{ Radiotherapy regimen } \\
\hline Shorter course $(n=4)$ & 50 & 50 & \\
\hline Longer course $(n=18)$ & 67 & 39 & 0.72 \\
\hline \multicolumn{4}{|l|}{ Age } \\
\hline$<60$ years $(\mathrm{n}=11)$ & 55 & 36 & \\
\hline$\geq 61$ years $(n=11)$ & 73 & 45 & 0.28 \\
\hline \multicolumn{4}{|l|}{$\begin{array}{l}\text { Period from cancer } \\
\text { diagnosis until MESCC }\end{array}$} \\
\hline$\leq 15$ months $(\mathrm{n}=8)$ & 38 & 38 & \\
\hline$>15$ months $(\mathrm{n}=14)$ & 79 & 43 & 0.49 \\
\hline \multicolumn{4}{|l|}{ Visceral metastases } \\
\hline No $(n=10)$ & 100 & 80 & \\
\hline Yes $(n=12)$ & 33 & 8 & $<0.001$ \\
\hline \multicolumn{4}{|l|}{ Other bone metastases } \\
\hline No $(n=11)$ & 91 & 55 & \\
\hline Yes $(n=11)$ & 36 & 27 & 0.06 \\
\hline \multicolumn{4}{|l|}{$\begin{array}{l}\text { Dynamic of developing } \\
\text { weakness of the legs }\end{array}$} \\
\hline Fast ( $\leq 14$ days) $(\mathrm{n}=11)$ & 45 & 9 & \\
\hline Slow ( $>14$ days) $(n=11)$ & 82 & 73 & 0.008 \\
\hline \multicolumn{4}{|l|}{ Gait function prior } \\
\hline \multicolumn{4}{|l|}{ to radiotherapy } \\
\hline Ambulatory $(\mathrm{n}=10)$ & 75 & 67 & \\
\hline Not ambulatory $(\mathrm{n}=12)$ & 50 & 10 & 0.005 \\
\hline \multicolumn{4}{|l|}{$\begin{array}{l}\text { Number of vertebrae } \\
\text { affected by MESCC }\end{array}$} \\
\hline $1-2$ vertebrae $(n=13)$ & 85 & 54 & \\
\hline$\geq 3$ vertebrae $(n=9)$ & 33 & 22 & 0.020 \\
\hline \multicolumn{4}{|l|}{ ECOG performance score } \\
\hline $1-2(n=5)$ & 100 & 100 & \\
\hline $3-4(n=17)$ & 53 & 24 & 0.012 \\
\hline
\end{tabular}

MESCC, Metastatic epidural spinal cord compression; ECOG, Eastern Cooperative Oncology Group; bold values, significant $p$-values.

In this study, a scoring instrument was developed that allows for estimation of OS in patients with gynecological cancer who experienced MESCC. Based on two independent prognostic factors, visceral metastases and the number of vertebrae affected by MESCC, an instrument was created that included three prognostic groups $(0,1$ and 2 points) with significantly different OS rates. In the 0-point group, no patient survived 3 months or longer. Therefore, these patients appear to be good candidates for a less burdensome short radiotherapy program, such as $20 \mathrm{~Gy}$ in 5 fractions over 1 week or 8 Gy in 1 fraction, since these regimens were reported to have similar effects on motor function as longer lasting programs, such as $30 \mathrm{~Gy}$ in 10 
Table II. Results of the multivariate analysis of overall survival.

\begin{tabular}{|c|c|c|c|c|}
\hline & & $\begin{array}{l}\text { Hazard } \\
\text { ratio }\end{array}$ & $\begin{array}{c}95 \% \text {-confidence } \\
\text { interval }\end{array}$ & $p$-Value \\
\hline Visceral metastases & no $v s$. yes & 14.53 & 2.16-154.39 & 0.004 \\
\hline Dynamic of developing weakness of the legs & $\leq 14$ vs. $>14$ days & 1.04 & $0.49-2.60$ & 0.92 \\
\hline Gait function prior to radiotherapy & ambulatory $v s$. not ambulatory & 1.51 & $0.49-5.45$ & 0.49 \\
\hline Number of vertebrae affected by MESCC & $1-2 v s . \geq 3$ vertebrae & 2.20 & $1.19-4.39$ & 0.012 \\
\hline ECOG performance score & $1-2$ vs. 3-4 & 1.04 & $0.09-25.10$ & 0.98 \\
\hline
\end{tabular}

MESCC, Metastatic epidural spinal cord compression; ECOG, Eastern Cooperative Oncology Group; bold values, significant $p$-values.

fractions, $37.5 \mathrm{~Gy}$ in 15 fractions and $40 \mathrm{~Gy}$ in 20 fractions given over 2, 3 and 4 weeks, respectively (11). In the 1point group, the majority of patients survived 3 months but only one third 6 months or longer. For these patients, radiotherapy with $20 \mathrm{~Gy}$ in 5 fractions appears appropriate. Highly selected patients with a good performance score may be considered for additional decompressive surgery performed prior to radiotherapy (4). Patients of the 2-point group had the most favorable OS prognosis achieving 6- and 12-month OS rates of $86 \%$ and $69 \%$, respectively (Figure 1). These patients would likely benefit from longer lasting radiotherapy, such as $30 \mathrm{~Gy}$ in 10 fractions, $37.5 \mathrm{~Gy}$ in 15 fractions or $40 \mathrm{~Gy}$ in 20 fractions. These regimens were reported to achieve better local control of MESCC (freedom from an in-field recurrence of MESCC in the irradiated portion of the spine) than shorter-course programs $(6,12)$. The risk of developing an in-field recurrence of MSCC increases with duration of life. Thus, patients having a 2-point score carry a greater risk of a recurrence than patients of the 0-point score and the 1-point score group. Similar to the 1-point group, selected patients of the 2-point group may be considered for decompressive surgery prior to radiotherapy. When considering these recommendations, one should be aware of the small sample size of this study and the retrospective nature of the data used for creating the scoring instrument. These aspects may have led to the inclusion of hidden selection biases, which could be avoided in a prospective randomized trial. However, since patients with MESCC from gynecological cancers are scarce, trials are unlikely to be performed. Thus, retrospective data represent the best information available.

In conclusion, the new scoring instrument, including three prognostic groups with significantly different OS times, can support physicians when picking an individual treatment for patients with MESCC from gynecological malignancies.

\section{References}

1 Prasad D and Schiff D: Malignant spinal cord compression. Lancet Oncol 6: 15-24, 2005.

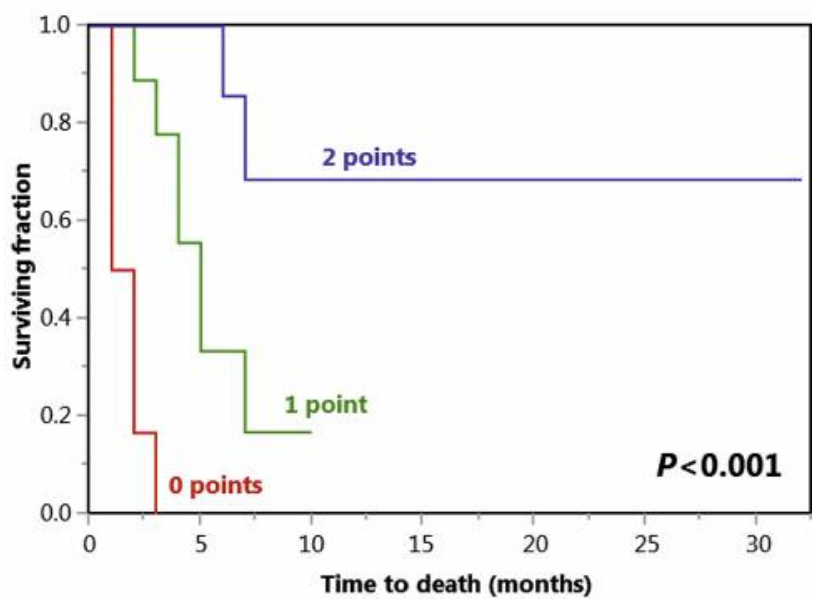

Figure 1. Kaplan-Meier curves for overall survival of patients with 0 , 1 and 2 points.

Table III. Scoring points related to the factors significantly associated with overall survival on multivariate analysis.

\begin{tabular}{lc}
\hline & Scoring points \\
\hline Visceral metastases & \\
No & 1 \\
Yes & 0 \\
Number of vertebrae affected by MESCC & \\
1 -2 vertebrae & 1 \\
$\geq 3$ vertebrae & 0 \\
\hline
\end{tabular}

MESCC, Metastatic epidural spinal cord compression.

2 Rades D and Abrahm JL: The role of radiotherapy for metastatic epidural spinal cord compression. Nat Rev Clin Oncol 7: 590598, 2010.

3 Rades D, Schild SE and Dunst J: Radiotherapy is effective for metastatic spinal cord compression in patients with epithelial ovarian cancer. Int J Gynecol Cancer 17: 263-265, 2007. 
4 Patchell R, Tibbs PA, Regine WF, Payne R, Saris S, Kryscio RJ, Mohiuddin $M$ and Young B: Direct decompressive surgical resection in the treatment of spinal cord compression caused by metastatic cancer: a randomised trial. Lancet 366: 643-648, 2005.

5 Rades D, Šegedin B, Conde-Moreno AJ, Garcia R, Perpar A, Metz M, Badakhshi H, Schreiber A, Nitsche M, Hipp P, Schulze W, Adamietz IA, Norkus D, Rudat V, Cacicedo J and Schild SE: Radiotherapy with 4 Gy $\times 5$ versus 3 Gy $\times 10$ for metastatic epidural spinal cord compression: Final results of the SCORE-2 Trial (ARO 2009/01). J Clin Oncol 34: 597-602, 2016.

6 Rades D, Fehlauer F, Schulte R, Veninga T, Stalpers LJ, Basic $\mathrm{H}$, Bajrovic A, Hoskin PJ, Tribius S, Wildfang I, Rudat V, Engenhart-Cabilic R, Karstens JH, Alberti W, Dunst J and Schild SE: Prognostic factors for local control and survival after radiotherapy of metastatic spinal cord compression. J Clin Oncol 24: 3388-3393, 2006.

7 Rades D, Schild SE, Karstens JH and Hakim SG: Predicting survival of patients with metastatic epidural spinal cord compression from cancer of the head-and-neck. Anticancer Res 35: 385-388, 2015.

8 Rades D, Dahlke M, Janssen S, Gebauer N and Bartscht T: Radiation therapy for metastatic spinal cord compression in patients with hepatocellular carcinoma. In Vivo 29: 749-752, 2015.
9 Rades D, Conde-Moreno AJ, Garcia R, Veninga T and Schild SE: A Tool to Estimate survival of elderly patients presenting with metastatic epidural spinal cord compression (MESCC) from cancer of unknown primary. Anticancer Res 35: 6219-6222, 2015.

10 Rades D, Conde-Moreno AJ, Cacicedo J, Segedin B, Veninga T and Schild SE: Metastatic spinal cord compression: A survival score particularly developed for elderly prostate cancer patients. Anticancer Res 35: 6189-6192, 2015.

11 Rades D, Stalpers LJA, Veninga T, Schulte R, Hoskin PJ, Obralic N, Bajrovic A, Rudat V, Schwarz R, Hulshof MC, Poortmans $\mathrm{P}$ and Schild SE: Evaluation of five radiation schedules and prognostic factors for metastatic spinal cord compression. J Clin Oncol 23: 3366-3375, 2005.

12 Rades D, Lange M, Veninga T, Stalpers LJA, Bajrovic A, Adamietz IA, Rudat V and Schild SE: Final results of a prospective study comparing the local control of short-course and long-course radiotherapy for metastatic spinal cord compression. Int J Radiat Oncol Biol Phys 79: 524-530, 2011.

Received August 16, 2016

Revised August 26, 2016

Accepted August 29, 2016 